Article

\title{
Against the Odds: Insights from a Statistician with Dyscalculia
}

\author{
Katherine E. Lewis ${ }^{1, *}$ and Dylan M. Lynn ${ }^{2}$ \\ 1 College of Education, University of Washington, Seattle, WA 98195, USA \\ 2 Independent Researcher, Seattle, WA 98195, USA; dylanlynn.edu@gmail.com \\ * Correspondence: kelewis2@uw.edu; Tel.: +1-206-221-4738
}

Received: 28 February 2018; Accepted: 19 April 2018; Published: 26 April 2018

\begin{abstract}
Students with dyscalculia are typically thought of by both researchers and educators as having deficits. The deficit language permeates studies of dyscalculia as well as assessments and documentation of students in schools. In this paper, we offer an alternative to the dominant narrative. We understand disabilities, and dyscalculia specifically, as resulting from cognitive differences-not deficits-which lead to issues of access. We provide a case study of Dylan (second author), an individual with dyscalculia who decided to major in statistics at University of California, Berkeley and become a statistician. Although she experienced significant issues of access—both in the standard tools used to do mathematics, and in navigating the structures at the university - she developed systems to enable her to compensate. She collaborated in this research enterprise in order to share with researchers, teachers, parents, and students her experiences with dyscalculia and how she was able to succeed in higher level mathematics. Informed by previous empirical work, we collected video recordings of Dylan's deliberate efforts to share insights and strategies with another student with dyscalculia. In this work, Dylan challenges dominant and problematic myths about ability and mathematics.
\end{abstract}

Keywords: dyscalculia; learning disability; mathematics; access; accommodations; compensation; myths; case study; disability studies; emancipatory research

\section{Introduction}

"We don't say people with dyslexia will never learn to read, so we shouldn't say that people with dyscalculia can never learn to do math."

(Dylan; second author)

In this paper we draw upon Dylan's experience having both dyscalculia and majoring in statistics at University of California, Berkeley before going on to work as a data analyst for 4 years. Not only is it assumed that a student like Dylan would not be able to major in mathematics, but she was told by countless well-meaning advisors, teachers, and professors that she should switch majors. We use Dylan's case to challenge the myth that individuals with dyscalculia cannot be successful in higher level mathematics. Although Dylan did experience significant issues of access over the course of her educational career, Dylan developed a complex repository of tools and compensatory strategies that enabled her to address these issues of access and succeed [1,2].

Approximately $6 \%$ of all students have dyscalculia (also referred to as a mathematics learning disability) [3,4]. Students with dyscalculia have a neurological difference in how their brains process numerical information [5]. For example, students with dyscalculia have been found to be slower and more error prone than their peers when processing symbolic (e.g., 5) and non-symbolic (e.g., ${ }^{* * * * *)}$ representations of number [6]. These kinds of number processing issues can lead to significant 
difficulties learning and doing mathematics [7]. Although research on dyscalculia has identified several ways in which students with dyscalculia have different patterns of difficulties than their peers [8-10], we identify several issues with the traditional approaches used to study this disability. First, research on dyscalculia has predominantly framed this disability in terms of deficits [11]. These deficits are often defined and quantified by comparisons between students with and without dyscalculia on measures of speed and accuracy (e.g., [12]). This deficit perspective presumes that the disability is due to an internal and biologically-based deficiency, which implies that students with dyscalculia cannot succeed in mathematics. Second, research on dyscalculia has almost exclusively focused on mathematics concepts introduced during early elementary school (e.g., arithmetic) [13]. The lack of studies documenting dyscalculia with older students in advanced mathematics could be attributed to a deficit-based presumption that students must master the basics before they can engage in any higher-level mathematics. Therefore, much attention has been focused on the difficulty that students with dyscalculia experience with memorizing and retrieving basic number combinations (e.g., $4+5=9$ ) often to the exclusion of all else [14].

This deficit-oriented perspective on dyscalculia has had ramifications for how researchers and educators understand this disability and has contributed to specific myths about dyscalculia and mathematics. In this paper, we address and push back on the following myths:

Myths about dyscalculia:

- Dyscalculia results from inherent cognitive deficits within the individual;

- Students with dyscalculia cannot learn or do higher-level mathematics.

Myths about mathematics:

- Students must master the "basics" to succeed in higher-level mathematics;

- Speed and efficiency are important to succeed in mathematics.

We argue that these myths permeate beliefs that researchers, teachers, and parents have about students with dyscalculia and have in many circumstances been codified in policies and practices governing students (e.g., individualized education programs, curriculum-based measurements). In this paper, we offer an alternative vantage point to the prevailing deficit notions about disability, and allow Dylan-a statistician with dyscalculia—to provide insight into her experiences. She serves as an existence proof countering these common myths about ability and mathematics.

In this section, we describe how our unique theoretical and methodological approach enables us to disrupt and push back against the dominant myths perpetuated by traditional research on dyscalculia. First, we reconceptualize dyscalculia as a cognitive difference, rather than a cognitive deficit. Second, we use an emancipatory research approach [15], in which the individuals with disabilities are deeply involved in all aspects of the research process.

\subsection{Understanding Dyscalculia as Difference}

In our work, we reject the deficit model, which assumes that disability is an internal and inherent characteristic of the student (see Figure 1) and we reframe dyscalculia as a cognitive difference [16]. This difference does matter; not all tools, spaces, and contexts are equally accessible to all people. Standard tools, which have developed over human history to be optimized for individuals with typical development, may not be accessible to individuals with disabilities [16]. For example, just as printed text may not be accessible to a blind individual, mathematical symbols, manipulatives, and pictures may not be accessible to an individual with dyscalculia because of a difference in how they process numerical information. This reframing of disability in terms of difference identifies the "problem" as the inaccessibility of material tools rather than attributing this to some internal characteristic of the student (see Figure 1).

However, just because the canonical tools are not accessible does not mean that the individual cannot access the content through other means. When an individual's physical, neurological, or perceptual 
differences render a standard tool inaccessible, there are two possible options. First, alternative tools that are accessible can be developed and used, as is the case with Braille. Second, an individual can compensate [16]. We understand compensation to be an individual's deliberate action leveraging alternative resources to gain access to an otherwise inaccessible space, content, or context. For example, some blind individuals echolocate (i.e., use sound like radar) to navigate physical spaces [17]. The same goal can be achieved, but the means of achieving that goal are different. This focus on difference and compensation shifts our attention to trying to understand what students do, rather than documenting and quantifying what they cannot do. Therefore, in our analysis, we focus on the tools that Dylan used and how she compensated to gain access to mathematics.

\section{Deficit View}

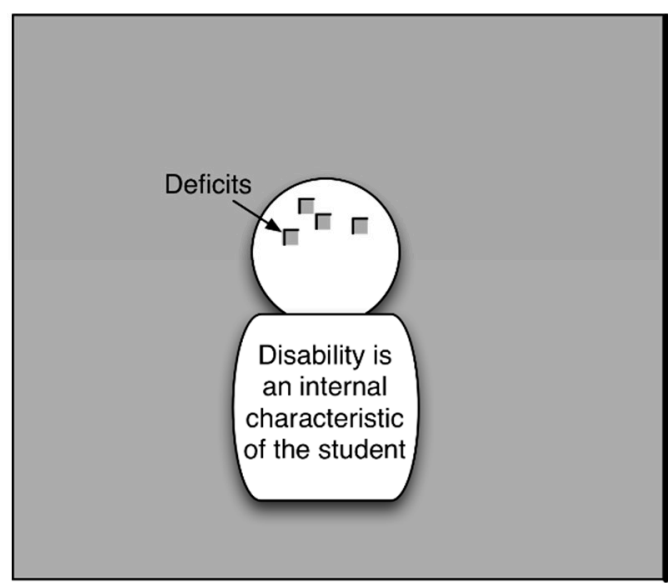

Figure 1. Illustration contrasting a deficit view and a difference view of dyscalculia.

\subsection{Emancipatory Research Approach}

Another unique characteristic of this research is its collaborative nature. Disability advocacy groups argue that individuals with disabilities should be included throughout the research process rather than subjected to non-disabled researchers' agendas [15]. This kind of collaboration between researcher and participant is referred to as emancipatory research, because it inverts the traditional power dynamic and places the authority in the hands of the individuals with disabilities $[15,18]$. An emancipatory approach enables individuals with disabilities to push back on oppressive structures that limit access because the individuals with disabilities have agency over the research questions, data collection, analysis, and dissemination $[19,20]$. In writing this manuscript, we attempt to fulfill the goals of emancipatory research [19]. First, we achieve Dylan's primary goal to share her knowledge with teachers, parents, and students. Second, we critique the systemic and structural barriers that Dylan encountered as a student and propose alternatives to increase access for students with dyscalculia.

\subsection{Role of the Researchers}

Dylan initiated this research collaboration by contacting Katie (first author) when she was a senior statistics major. Dylan had experienced significant, persistent, and pervasive issues with mathematics but was determined to major in statistics because she found it interesting. She had struggled with math throughout her life, but when she got to college she started failing her classes. "I did so well in all my other courses, but there was this one area, math, that I had a hard time with. [My advisor] suggested that I get screened by an educational psychologist". The testing revealed that Dylan had unusual difficulties; she explained, "I can do addition and subtraction but it takes me a lot longer than it should. And that's where the educational psychologist said it's highly unusual, you probably have dyscalculia, especially for someone who's taken all these hard math classes, but it's taking you so long 
to do a lot of these basic arithmetic things". Dylan received accommodations for having a disability that specifically impacted her ability to do mathematics (see [2] for more information). After becoming frustrated with the lack of accommodations and supports, she connected with the students' disabilities group on campus and learned about Katie's research.

Dylan contacted Katie to try to learn about strategies that students with dyscalculia can use for higher level mathematics. Katie explained that unfortunately she was unable to provide Dylan any direct assistance because she had never taken the upper division mathematics courses that Dylan was enrolled in. In this first meeting, Katie shared a little about her research and her own experiences having been diagnosed with a language-based learning disability (i.e., dyslexia). Katie informed Dylan that there was not a documented case of an individual with dyscalculia who majored in mathematics. Together, Dylan and Katie decided to document both the difficulties that Dylan experienced as well as how she had learned to compensate. Dylan's goal in engaging in this research was wide dissemination of her hard-fought knowledge so that others would not have to go through what she did. She wanted to share with researchers, teachers, parents and students what she had learned and how she had succeeded in mathematics despite the issues of access she encountered. We have published empirical results of this research collected during Dylan's senior year elsewhere [1,2]. As in the case with emancipatory research, Dylan was involved in the design, analysis, and writing of this empirical work (see [2] for details). In this manuscript, we report on video data collected this year in which Dylan shared her strategies with the hope that it would be beneficial to others. In this research, we acknowledge Dylan's status as an expert on dyscalculia who is ideally positioned to help others.

\section{Methods}

In order to highlight the issues of access Dylan experienced and the ways she learned how to compensate, we used video recordings of Dylan sharing her experiences in two contexts. First, Dylan met with another college student with dyscalculia ("Cindy"). During this session, Dylan shared her experiences and provided advice and recommendations to help Cindy address her own difficulties. Second, Katie interviewed Dylan about her experiences learning and doing mathematics. During the interview, Dylan solved several mathematics problems of varying difficulty, discussed her general approaches for compensating, and described the tools and systems that she put in place that enabled her to succeed. The interview provided an opportunity for Dylan to discuss her use of particular tools (e.g., graph paper, pencils) that were not available during the session with Cindy. These two data sources provide complementary data and are integrated in the findings. Both video recordings were content logged and selectively transcribed. All video data was collected in accordance with University of Washington's Institutional Review Board policies and procedures.

The video records were analyzed with iterative passes through the data and were coded for (a) Dylan's reported difficulties or issues accessing the mathematics; (b) the structural barriers she faced as a statistics student with dyscalculia; (c) compensatory strategies Dylan used to address issues of access; and (d) recommendations for tools and instructional approaches that may be beneficial for students with dyscalculia. In this coding effort, we drew upon the operational definitions we produced in our previous analyses of Dylan's compensatory processes [1,2]. The coding scheme for this was developed by both authors and a research assistant, and then all data were systematically coded by at least two coders (see [1,2] for more details). The compensatory strategies identified and presented here align with those identified in our previous work [1,2]. Member checks were naturally embedded within the process as Dylan collected the data and collaborated with Katie in analysis and writing. To ensure that Dylan's voice is central in these findings, we use quotes taken from the video recorded sessions. In some cases, we have removed some irrelevant talk to make the quotes easier to read. Although we have co-written this paper, we use the third person throughout the paper for clarity. 


\section{Results}

We begin by presenting a description of the difficulties Dylan encountered as a student and an overview of the physical tools and compensatory strategies she used to make mathematics accessible. Second, we provide a detailed illustration of each of the compensatory strategies. As we discuss each strategy, we highlight Dylan's issues of access, the specific ways she compensated, and the additional demands implementing each compensatory strategy placed on her. Third, we report on the structural barriers that Dylan encountered as she completed her degree in statistics. Finally, we present Dylan's recommendations for educators working with students who may have dyscalculia.

\subsection{Overview of Dylan's Issues of Access, Tools, and Compensatory Strategies}

Dylan experienced significant, persistent, and pervasive issues with mathematics. Dylan explained that she had difficulty inverting numbers (e.g., writing 18 as 81), distinguishing mathematical symbols, understanding dense mathematical notation (e.g., fractions), and understanding the magnitude of numbers and how operations might affect numerical values. To address these difficulties, Dylan developed a repository of tools and compensatory strategies that enabled her to access mathematics. Dylan used a collection of physical tools that she explained was essential for her to do mathematics, which included

- Graph paper (4 squares per inch) to help her align and space her notation;

- Mechanical pencils to ensure a consistently sized lead thickness;

- A retractable eraser to enable her to erase precisely; and

- Colored pens to color code her notes and help her track various symbols and elements.

She used these tools along with the following compensatory strategies when learning and doing mathematics:

1. Rewriting in words—she translated mathematical symbols into words (e.g., 3 as "three");

2. Creating a dictionary - she created an internally consistent and differentiated way of writing each mathematical symbol so it had only one meaning and was not perceptually confused with other symbols;

3. Rewriting for consistency-she rewrote problems in a consistent form to make use of space to maintain clarity about her solution process;

4. Consistent solution process - she developed and used consistent solution processes to solve particular kinds of problems; and

5. Grounding the abstract-she grounded her understanding of values and mathematics concepts in real-world examples.

We illustrate each of these compensatory strategies below using examples and excerpts drawn from the video recordings. Note that during the sessions with Cindy, although they discussed tool use, Dylan used felt-tipped markers for visibility within the video and did not have access to her standard complement of tools.

\subsubsection{Rewriting in Words}

Dylan had difficulty understanding and tracking the meaning of mathematical symbols. She explained one of her strategies to make sense of notation was to rewrite the mathematical symbols in words. This helped her understand the meaning of the symbols and helped her solve problems. She gave an example of how she would write out a problem like $5+3=$ to help her make sense of the symbols, and how this was a strategy she still used with higher-level mathematics such as calculus.

Dylan: "I am stronger with language, so this is a thing that I did when I was a kid. And then I actually started doing it-it came up more in my higher level math classes. If I have like five plus three equals eight [writes $5+3=8$; see Figure 2], I actually do really well with language. [writes out "five plus three equals eight"]". 
By translating the symbols into words, she would more readily be able to connect the symbols to their underlying meaning. She explained that mathematical notation was a condensed notational form of writing words; "math is shorthand for this [points to "five plus three equals eight"]". It was this "shorthand" for quantities that Dylan found hard to access, which was why she routinely translated these kinds of symbols into words. When explaining this approach to Cindy, she went on to give an example for calculus and how she would regularly translate function notation (i.e., $f(x)$ ) into words to make it more understandable.

Dylan: "This is calculus, but you can see it illustrated with this notation [writes $f(x)=x+4 x^{3}$; see Figure 2] this notation, the way people say this is " $\mathrm{f}$ of $\mathrm{x}$ " which is also terrible. It's the function of $x$ equals this [as writing "function of $x=x+4 x^{3}$; see Figure 2]. This little notation here [points to $f(x)$ ] would throw me off really badly in my classes, because $f$ times $x$ ? No, it's a notation that is basically applying this function to the variable $x$. I would sometimes write out something like this [writes bracket underneath "function of $x$ "] right underneath whatever it was and again, this is really verbose, [but] it might be helpful."

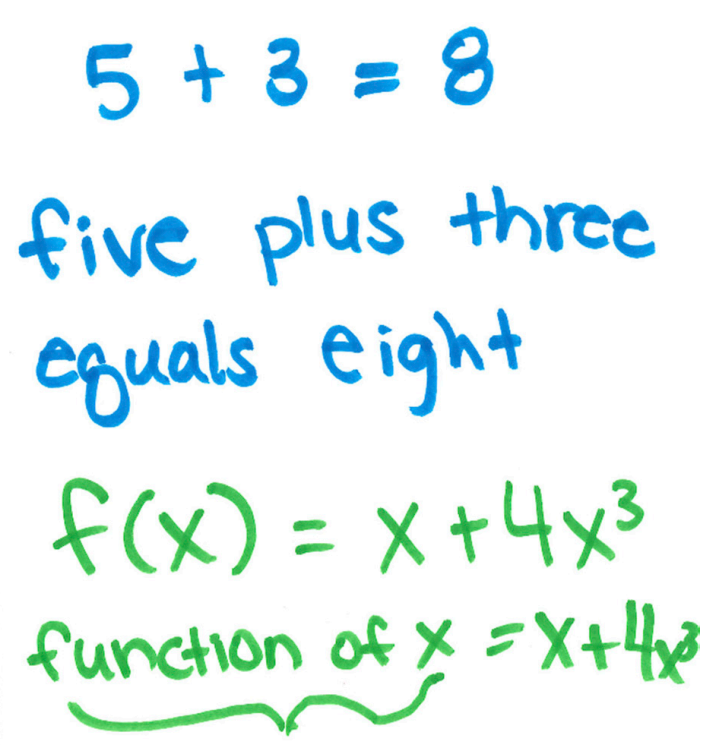

Figure 2. Dylan's examples of rewriting mathematical symbols with words, which helped her translate and make sense of the meaning of the notation.

Dylan noted that she often used this kind of translation in her notes to help her decode the meaning of the symbols, and described it as her creation of metadata for the notation. For example, she would translate the notation $\mathrm{P}(\mathrm{A} \mid \mathrm{B})$ into "probability of A given B" (see Figure 3). This rewriting into words was essential when she was learning new concepts or new notation.

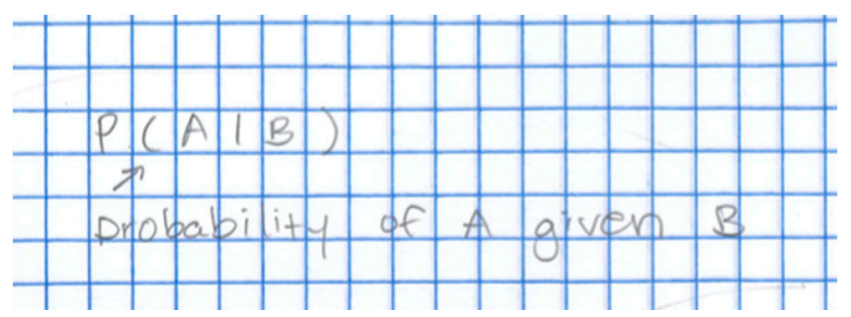

Figure 3. Example of Dylan's translation from mathematical symbols, $\mathrm{P}(\mathrm{A} \mid \mathrm{B})$, into words. 
This translation of symbols into words took Dylan extra time both when writing notes and when solving problems. Because this kind of translation was not available in her classes or textbooks, she paid tutors to provide this kind of support. She explained that "I would force tutors to give me the English words for the symbols, which was always funny because these are grad students who haven't thought about this stuff in years. 'How would you use this in a sentence? I haven't thought about it that way'". The kinds of supports that Dylan needed were not something that the tutors were skilled at providing. Although this compensatory strategy provided her with a way of understanding the mathematical symbols, it placed additional demands upon her requiring that she spend more time and money than her peers to have access to mathematics.

\subsubsection{Creating a Dictionary}

Not only did Dylan experience difficulty understanding and decoding symbols, but she experienced issues of access when mathematical symbols were perceptually similar. She perceived several numerals to be perceptually similar and explained that, "I have a hard time with ones and sevens; and threes and eights", she also had difficulty differentiating her fours from her nines and her sixes from her fives. To address these issues, Dylan created her own system of distinct and consistent ways of writing each symbol, which she referred to as her dictionary. "That is one of the techniques I rely upon really heavily: [I'm] super consistent in the ways I write things and the notation I decide on. Trying my best to make it really distinct, so my ones don't look like my sevens and my threes don't look like my eights". The perceived perceptual similarity was not limited to the 10 numeral symbols. For example, she explained her difficulties differentiating the symbol $x$ from upper case $X$ and the plus sign.

Dylan: "There is the lower-case $x$ and the upper-case $x$, and God forbid you rotate it and it looks like a plus. Coming up with some distinct way so that I know what my variable means and then the language that I associate with the way that looks right."

One of her primary goals was to "make [mathematical symbols] very distinct from one another", so that when she saw the symbol she was able to tell what it referred to. "I [have] come up with a really consistent form of notation, so it's unambiguous". Because she had difficulty in differentiating both number symbols and other mathematical notation, she explained: "I was dogmatic about how clean and crisp I wrote my notation to differentiate it as much as possible". This was one of the reasons she relied so heavily upon mechanical pencils that could provide lines of uniform weight and a retractable eraser to erase precisely.

Dylan also had difficulty if one symbol was used for two different meanings (e.g., $\mathrm{x}$ standing for both the multiplication operation and an unknown). She explained how sometimes "one symbol has multiple meanings. And math is really lazy and they tend to reuse [notation] to mean different kinds of things". She explained that she would differentiate the different meanings by writing each symbol in distinct ways depending upon the context.

Dylan: "So I would be taking two math courses in the same semester and one would use an " $\mathrm{r}$ " for one meaning and one would use an " $\mathrm{r}$ " for another meaning. I would have to do a lower-case $\mathrm{r}$ for that class and an upper-case $\mathrm{r}$ for this class."

Although this often enabled her to differentiate the meanings of the same symbols, "I had to sometimes go back and reassess". One of the challenges of maintaining this system was that as she moved through higher-level mathematics courses she would need to revise her dictionary. She explained: "Then, the next semester I would take a different class and all of a sudden the $r$ would have a third meaning and I would have to reassess my dictionary". Although this dictionary enabled her to access and understand the meaning of symbols consistently, it was challenging to maintain, particularly as the mathematics notation got more complex and symbols were reused for new purposes. 


\subsubsection{Rewriting with Consistency}

Dylan also experienced issues of access with the density of mathematical symbols. She often would rewrite problems to space her notation out in a uniform way. For example, when given a problem in a book or on a test, she would rewrite the problem in her own handwriting often using graph paper, in which each symbol occupied one square of the graph paper (see Figure 4).

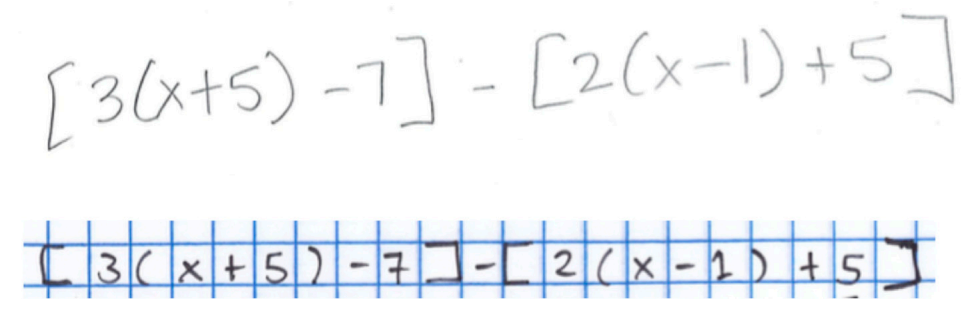

Figure 4. Problem written by Katie and rewritten by Dylan on graph paper using one box for each symbol.

Dylan: "Another thing I do is, although I could have started working off your problem, I won't. I'll rewrite it in my own handwriting. One, because I'm familiar with my handwriting. And two, because it forces me to rewrite the problem again, so I know what I'm solving."

Dylan's rewriting would enable her to use her dictionary of consistent and distinct symbols to rewrite the problems into an accessible format. "When you see the symbol, the first thing I do is, depending upon what type of problem I'm doing, I rewrite it in my handwriting that I have identified as unambiguous." When there were multiple canonical or acceptable ways to write a problem, she would rewrite the problem using the form that she preferred. "I come up with whatever operator I'm most comfortable with and before I even attempt a math problem, I rewrite it." She gave examples of how she handled both multiplication and division, which had multiple notations that were not all equally accessible for her. For example, multiplication can be represented with an $\mathrm{x}$, a dot (i.e., $\bullet$ ), or with parentheses. Although she had used a dot for multiplication throughout high school, she found that this was problematic in her advanced mathematics courses. "It becomes problematic in higher level math beyond this, in linear algebra it means something else." She also avoided using the dot as multiplication because it could be confused with a decimal: "I'm also careful with it because of decimals-it floats up and down [gestures up and down with pointer finger]." Because the dot had a different meaning in linear algebra and because the dot could be mistaken for a decimal point, Dylan would rewrite any problem that used the dot symbol for multiplication. She gave an example of the problem: $4 x \bullet 3=5$.

Dylan: "So let's say we have the problem $4 x$ times 3 equals 5 [writes $4 x \bullet 3=5$; see Figure 5]. If I saw this written down, I will actually rewrite it like this [writes $4 x(3)=5$; see Figure 5], so parentheses are used as multiplication. I come up with a really consistent form of notation, so it's unambiguous."

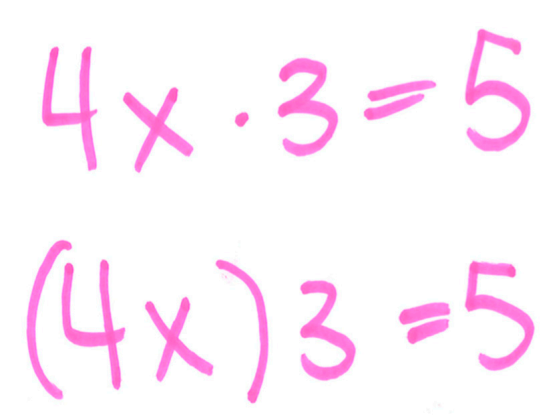

Figure 5. Dylan's illustration of how she would rewrite the problem $4 x \bullet 3=5$ as $4 x(3)=5$ to remove the problematic dot symbol for multiplication. 
Similarly, notation for division was also problematic; Dylan found the standard division symbol inaccessible. For the problem $6 \div 3=$ she explained, "This is terrible [pointing to the division sign in $6 \div 3=$ ] is it the 3 divided by the 6 or the 6 divided by the 3?" She also found the perceptual similarity of the long division sign and the square root sign to be problematic, so she tended to rewrite division problems using the fraction bar symbol.

Dylan: "Division [writes $\div$, see Figure 6 ] is typically taught like this to younger students. I despise this symbol, because I'm not sure what is acting on what. Long division is a little easier [writes long division sign to right of $\div$; see Figure 6]; however, long division, once you start doing square roots [writes square root sign below long division sign; see Figure 6], so I actually use the fraction symbol [draws fraction bar; see Figure 6]."

Although rewriting problems to use space and her preferred notation enabled Dylan to access the meaning of the mathematics symbols, she acknowledged that-like many of her compensatory strategies-it took more time and effort. For her, the tradeoff was worth it. She explained: "rewriting is another technique that I suggest for kids that adds more time, but increases my odds of accuracy."

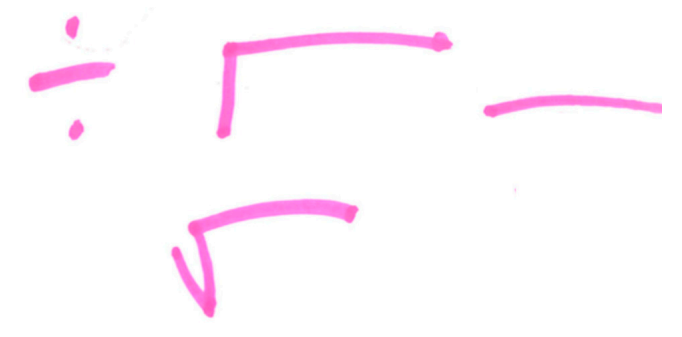

Figure 6. Dylan's written work when discussing various division notation options and her preferences (digitally modified to remove subsequent marks).

\subsubsection{Consistent Solution Process}

In addition to her difficulties with notation, Dylan described herself as having poor number sense [2]. She often had difficulty understanding the magnitude of quantities (e.g., fractions, negative numbers) and how operations might affect their values. To address this, Dylan relied upon a set of processes that helped her solve problems. The consistency of these processes enabled her to know and trust her answer, even if she had difficulty understanding the quantities involved. In our previous work [2] we identified six consistent processes that Dylan used across a range of mathematics topics. The consistent processes identified in our prior analysis were

1. Converting all fractions to a common base or language (i.e., denominator);

2. Showing all steps of her solution process;

3. Pulling out like terms (e.g., negatives or variables);

4. Distributing first to get rid of parentheses to simplify the problem;

5. Using her "abcd" method for solving fraction division problems (i.e., $\frac{\frac{a}{c}}{\frac{b}{d}}=\frac{a d}{b c}$ ); and

6. Solving problems as inverse operations.

We illustrate Dylan's explanation of two of these consistent processes (converting all fractions to a common base and showing all steps) and how these consistent processes enabled her to make sense of and solve problems. Then, we present an exemplar problem Dylan solved in the interview that illustrated many of her consistent processes in one problem.

Dylan had difficulty conceptualizing the relative magnitude of fractions, which made comparisons and operations with fractions challenging. "It's a very dense notation, when you think about the concept it's trying to portray." She often referred to fractions with different denominators as speaking 
different languages or having different bases. To address her difficulty in conceptualizing fractional magnitude, she used a consistent process of converting all fractions to a common denominator by multiplying the numerator and denominator by the denominator of the other fraction. For example, to compare the fractions $1 / 3$ and $1 / 4$, she explained that she would first determine a common base or language.

Dylan: "So this is the classic thing, that I see these two numbers and they aren't in the same language. I would immediately try to get these into the same common denominator so I can try to understand them. And that's where I have my cross multiplying thing that goes on [draws arrow between the denominator of each fraction and the numerator and denominator of the other fraction; see Figure 7], one of those little rules. So three times four, to get them into the same base is 12. So now I will have twelve on the bottom for both of them [writes /12 and /12], and to get this 4 times 3 is 12, 4 times 1 is 4 [writes 4]. And 3 times 4 is 12 and 3 times 1 is 3 [writes 3]. And now I can actually compare these two numbers [writes $>$ ]. The three is smaller and now I can rewrite them [writes $1 / 3>1 / 4] . "$
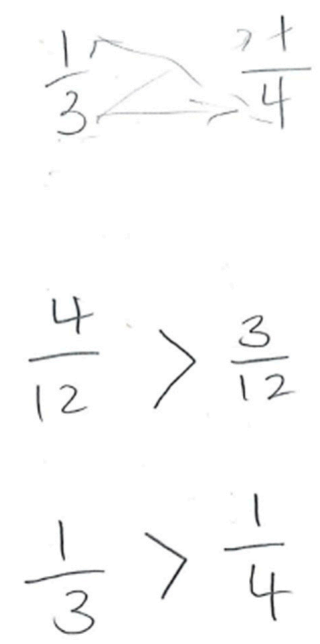

Figure 7. Dylan's written work for her comparison of $1 / 3$ and $1 / 4$.

In order to compare fractions, Dylan would convert them to a common denominator so that she could operate on the values as if they were whole numbers (e.g., comparing 3 and 4 and ignoring the denominator). After she determined the relationship, she then rewrote the fractions in the simplified and original form (1/3 and 1/4). Her use of the "language" analogy helped her understand how to operate on and conceptualize fractions, and she sometimes also used this language analogy to refer to like and unlike terms (as is seen in the next example).

The second consistent process involved Dylan showing every step of her solution process. Dylan sometimes had difficulty losing terms or symbols, and tracing a problem from one step to the next if multiple operations were performed simultaneously. To address these issues, as she solved problems, she represented each step of her solution process. This often involved more writing but it enabled her to understand the transformation from one step to the next and enabled her to catch her mistakes more easily. She gave an example of how she would write out every step when talking through her solution to the problem $12 x+5-3=6$.

Dylan: "I'm a big proponent of writing out every single step including anything that is intermediate even if it seems redundant. If I have [writes $12 x+5-3=6$; see Figure 8] and I wanted to solve for $x$. This is actually a good one. I'll just go through it with my steps of how I would do it, so you can see the way I think through problems. So, the first thing that I immediately see is that I want to start combining things that are similar. I use the word 
language a lot so these guys [points to 5 and 3] speak in the same language, because they are just numbers, this one [points to $12 x$ ] has a variable attached to it so it's speaking in a different language, there is one that is just a number [points to 6]. So, I'll start with the language that these guys are speaking. So, I'll rewrite twelve $\mathrm{x}$ [writes $12 x$ ] because I'm not going to do anything to it. Plus [writes +] I'm not doing anything to. Um, five minus three, now I've got 2 [writes $2=$ ]. I'm not doing anything to the 6 [writes 6]. Now I want to get rid of this two because it speaks the same language as the 6 . So I need to, and this is where my colors come in. So, I'm going to minus 2 from this side [writes -2] and minus 2 from this side [writes -2]. And sometimes I'll rewrite this out [writes $12 x+2-2=6-2$ ]. So, now I'm leaving the $12 x$ alone [writes $12 x$ ], two minus two is zero [writes +0 ]. This is one of the steps I may or may not do depending upon how much I have going on. Six minus two is 4. [writes 4]. Now I can get rid of my plus 0 , since it doesn't do anything $12 x=4$ [writes $12 x=4$ ]. I've got to get this 12 somehow over here, so I can isolate this $\mathrm{x}$ by itself. I know I can divide by 12 [writes /12] and divide by 12 [writes /12]. 12 divided by 12 is 1 . One $x$ equals four-twelfths [writes $1 x=4 / 12$ ]. This [pointing to 1] is redundant because 1 times $\mathrm{x}$ is just $\mathrm{x}$. [writes $x=4 / 12$ ] I can go further and simplify that, but I don't think I'll do that right now."

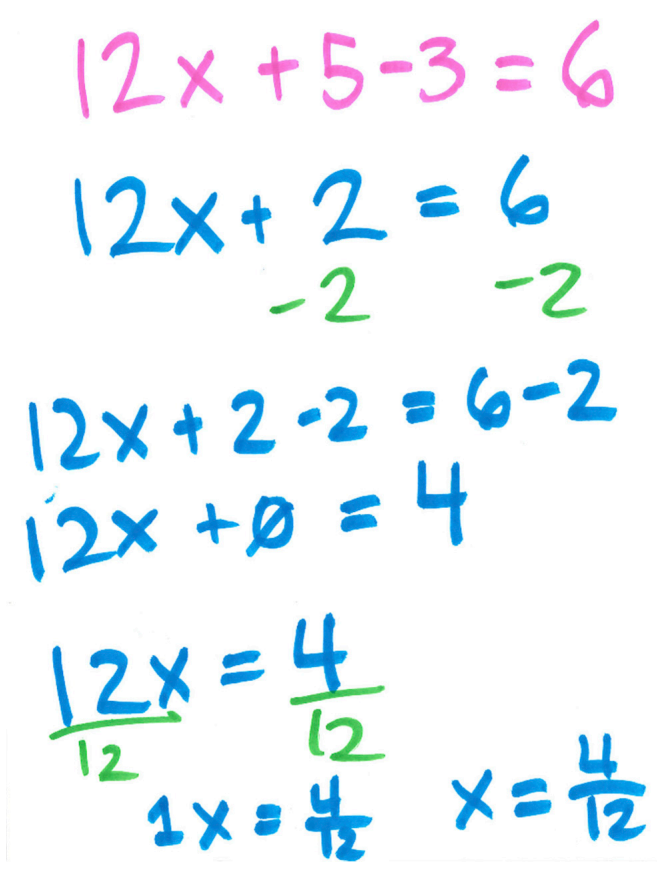

Figure 8. Dylan's written solution for $12 x+5-3=6$, illustrating how she shows all steps of her solution process.

As Dylan solved the problem she was careful to copy over each part of the problem that remained unchanged and made sure to only do one operation each step, often rewriting the equation so the operations were embedded within it rather than notated on a separate line. Dylan illustrated in this example how she used color to help her differentiate between the equation (blue) and the operations applied to the equation (green). Her deliberate effort to show all steps helped her track her progress through the problems and avoid mistakes.

To provide an example of how Dylan's consistent processes might make a problem lengthier, she explained how she would solve the problem $3(x+2)=1 / 2(3-x)$. Although most statistics majors might solve this in four or fewer steps (e.g., $6(x+2)=3-x ; 6 x+12=3-x ; 7 x=-9 ; x=-9 / 7$ ), Dylan solved this problem in 14 steps. Her written work (with annotations) illustrates how she used several of her consistent processes as she solved the problem (see Figure 9). 
In this problem, Dylan made sure to show every step of the solution process, and this included copying the original problem Katie had written into her own handwriting and copying the current equation verbatim when moving to a second sheet of paper. Both these reproductions were considered part of her step-by-step process because they were necessary for her to make sense of the symbols and to help her track the problem as she switched to a new sheet of paper. As she copied over the initial problem, she stated "Oh—-that's one-half, I was reading that as y2." Katie's representation with a slanted fraction bar was perceptually similar to a $y_{2}$ and so Dylan took the deliberate step of differentiating this notation. When she copied the equation verbatim onto her second page, she explained: "I'd recopy that over, this is why grad students hated grading my homework." Throughout this problem, she tended to operate on only one side of the equation at a time, copying the other side without any changes. She explained: "I try not to do multiple operations at once. [It's] also a good way to catch errors." As was often the case, Dylan's consistent processes (distributing first and always converting to a common denominator) resulted in her solving a more lengthy and complex problem.

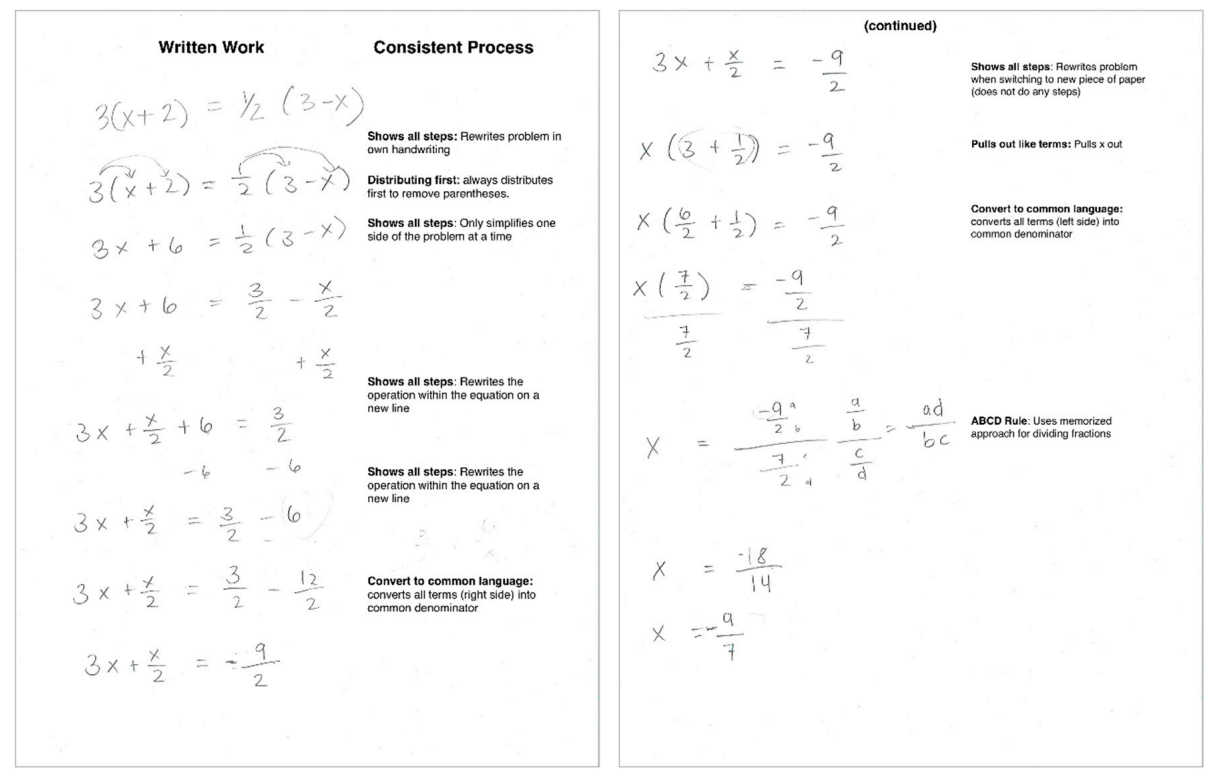

Figure 9. Dylan's written solution for $12 x+5-3=6$, illustrating how she shows all steps of her solution process.

As was evident in each of the examples, Dylan's consistent processes enabled her to make sense of hard to conceptualize values, and provided a consistent approach to solving problems to enable her to track her progress. This approach, however, often resulted in more time and effort because of the demands of each of the consistent processes and because implementing these processes sometimes led to her solving a problem in a less optimized way and therefore solving a more difficult problem.

\subsubsection{Grounding the Abstract}

Dylan had difficulty understanding abstract or decontextualized numbers, operations and concepts. She explained that numbers and concepts were often not sufficiently connected to meaningful contexts: "You learn this really abstract concept for $5+3=8$. What is the 5 ? What is the 3 ? What is the 8?" To try to make sense of numbers and concepts, she would try to connect these symbols and ideas to the real world. She recommended helping students develop a meaning of number by starting with manipulatives: "Now we have these objects and we can start to label them." "I found visual things to click with me a little bit better, if someone uses manipulatives." Dylan found that manipulatives helped her connect to the underlying meanings of the symbols, and having an opportunity to move, cut, combine and interact with these manipulatives was helpful for Dylan in conceptualizing quantities 
and operations on quantities. "When I'm struggling with a concept, if I can give it a really concrete foundation, it will stick with me much better."

In addition to concretely representing quantities with manipulatives, Dylan found it helpful if she could connect the concept to a real world application. Because she found mathematics connected to application easier to understand, she found statistics more accessible because it had an applied component where patterns in data were quantified.

Dylan: "The reason why it's funny that I did statistics, but it makes a lot of sense, is that if I could take one of these concepts and apply it to something that was actually tangible to me, so like the percentage of people that are over the age of 55 that have a landline phone, if I come up with these stories or narratives, then I could actually recall how to do an operation, but I had to have some sort of narrative that was actually based in the real world."

She found that the internet was a good resource for helping her understand the purpose behind particular concepts or ideas. "If you are approaching a subject, before you even dive into it just go out into the world of the internet and try to figure out how people even use this and then go back into the abstract." She explained,

Dylan: "Sometimes I would google "real life examples of blah blah blah" because even if it wasn't that exact problem, all the sudden if I could connect to that-Oh! That's why I need to know this. I really struggled with math when I was like "why are we learning this?"

Dylan found herself often turning to the internet for these kinds of real world connection because her tutors were often ill-equipped to provide this kind of grounding, which she described as "another big problem in the math community."

\subsection{Structural Barriers}

In her discussions with Cindy and her interview with Katie, Dylan identified several structural barriers she encountered. These were policies and practices which marginalized her participation in upper division mathematics classes. Dylan explained "in my first semester, I failed my two weeder classes." The "weeder" courses (e.g., calculus and linear algebra) are predicated on the assumption that if a student cannot pass the class, they are not enough of a "math person" to succeed. After being diagnosed with a disability, she was told that the primary accommodation for students with dyscalculia at UC Berkeley was to waive the university's mathematics requirement. We view this as an exclusionary practice, which, rather than accommodating for disabilities, excludes those individuals from participation in mathematics-and by extension all other STEM fields. Not only were the policies exclusionary, but she was actively discouraged from pursuing and completing her degree in statistics.

Dylan: "The math department is very unaccommodating. People in math tend to have an attitude of, if you can do it then great, if you can't, then you're just not meant to be. Which is ridiculous, because it's not acceptable to not be able to read, so I don't know how it's acceptable to not be able to do math. I got told that I should probably drop out of Berkeley and reapply the next semester into a different degree program. At this point I was a junior in college. Which is not really possible, it's like, no I'm committed."

The institutional policies and advising practices were exclusionary and Dylan was left to figure out how to navigate this system on her own.

Dylan: "The way I was able to get through was brute force. I had this professor, and she said there are two kinds of mathematicians: those that are smarter than everyone else, and those that work harder. And so I worked harder. I took classes multiple times, I created this incredible library of stuff, I have this really specific system of how I write and rewrite ... 
In order to learn a basic concept, I would attack it from every angle until something stuck. So it was just brute force, and working harder than everyone else. Which is frustrating, right? Because you are being asked to do a phenomenal amount more work than anyone else in this class has to do and it would be really lovely if we just lived in a world where we were given lots of options of all these different ways of learning this one particular concept. And unfortunately, right now you have to cultivate all these different ways yourself."

Not only did she have to spend considerably more effort than her peers just to transform the mathematics into a form that was accessible, but she was given no support to do this.

Although she was able to succeed by developing compensatory strategies, these all required more time and effort, which was not easily accounted for in the standard instructional or assessment approaches. Dylan explained how her compensatory strategies resulted in her having to take classes multiple times:

Dylan: “When I'm learning something, I try to remove myself really quick, and go learn why would I ever do this, what are the definitions of all these terms, then come up with my note taking system for how I'm going to do it, then I can dive into the subject. Needless to say, this is why I had to take so many classes in college a couple times."

Dylan's demanding compensatory strategies did enable her to access mathematics, but not always at the pace that she needed to pass her classes the first time through. Dylan remarked that taking classes multiple times was "very expensive," and paying for tutors placed an additional financial strain upon her.

In these sessions, Dylan identified time as the most significant structural barrier: "Time is always the hugest block." Implementing her compensatory strategies took more time, and this was time she was not afforded on assessments. She explained how this time constraint was arbitrary and did not match her experiences in her career as a data analyst.

Dylan: "It's really really unfortunate to me, I think that, in mathematics, it's not just that you understand the concept. It's not just that you can get a correct answer, you also have to do it in a certain amount of time, which inevitably is like this really bizarre artificial constraint. Especially now that I've worked in industry at as a data analyst. And yes, I had time constraints, I had to get a report done in this amount of time or whatnot. It's nothing like sitting down for a test and you have $60 \mathrm{~min}$ to do this insane page of stuff and this huge mental dump, where these kinds of rewriting things would really become problematic, I would just flat out run out of time. I would have to either not rewrite things and inevitably make mistakes or rewrite things and not finish exams. I would have to make calculated decisions at the beginning of exams."

Not only were the structures of assessment (time constraints) and the policies (weeder classes and disability waivers) sending messages to Dylan that she did not belong in upper division mathematics classes, but she often had graduate students devaluing her legitimate approaches to solving problems. In implementing her compensatory strategies, she often encountered resistance because she did show all her steps and methodically wrote and rewrote notation so that she could understand its meaning. "I would also frequently get the professor's assistants that would grade our work; they would gripe that my solutions were too long". Graduate students, prioritizing the economy of notation, identified Dylan's processes as problematic.

Dylan: "I had grad students-one in particular, I think it was multivariate calculus-he would write on the top of my assignments "please shorten steps" or whatever because he has to grade x numbers of assignments and he hated how verbose mine were."

Dylan experienced significant structural barriers in completing her statistics degree. These existed within the policies and practices at the institutional level, and also in her individual interactions with people tasked with evaluating her competency. 


\subsection{Instructional Recommendations}

Throughout the video recordings, Dylan made references to instructional recommendations she had for teachers, parents, and students. These recommendations came from her own experiences and were informed by two years of tutoring students with disabilities in mathematics. In Dylan's recommendations for instructing students with dyscalculia, several themes emerged.

1. Identify issues of access, particularly in notation. Dylan often assessed this by asking students to write out all numerals and mathematical symbols they knew. She noted if students inverted numbers (e.g., wrote 18 as 81), misread numbers (e.g., reading 6 as a 9), or confused operators (e.g., solved subtraction as addition). She would discuss any issues of perceptual similarity and suggest the student change the form of their notation or use graph paper or color to space and organize their notation sufficiently.

2. Identify and build on the student's strengths. Dylan asked students to explain their areas of strengths (e.g., language, organization) and would use this to think about how to support their understanding of mathematics. For example, she might have a student label their addition and subtraction problems with "add" or "sub" (see Figure 10) to help them attend to the difference in the operator symbol.

3. Connect the mathematics to something meaningful. Dylan recommended always contextualizing mathematics in terms of something that was concrete for the student, either physical manipulatives or real world contexts.

4. Teach and allow for multiple solution paths. Dylan recommended teaching multiple ways to understand a concept and multiple problem solving approaches. The value of a particular approach should be determined by whether it enables the student to make sense of the mathematics, rather than whether it is efficient (e.g., standard algorithms).

5. Give student agency over reflecting and determining what works for them. Dylan was careful not to generalize from her own experiences and repeatedly emphasized the importance of students figuring out what systems would work for them.

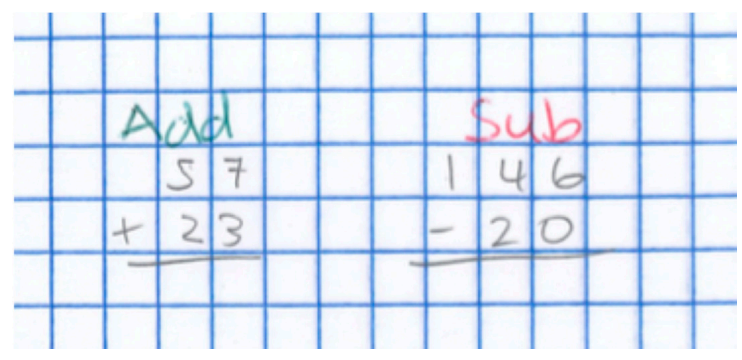

Figure 10. Illustration of how Dylan recommends that students she works with color code and use language to make clear what the mathematical operation means for each problem.

\section{Discussion}

Dylan's case provides unique insight into her experience majoring in statistics as a student with dyscalculia and enables us to counter common myths about disability and mathematics. We discuss each of the myths raised in the introduction in light of Dylan's case and call for shifts in policies and practices to address the kinds of structural barriers Dylan encountered. We argue that removal of barriers is the only way to disrupt these pervasive myths at a more systemic level.

\subsection{Countering the Myth: Dyscalculia Results from Inherent Cognitive Deficits}

In this paper, we reconceptualized dyscalculia as a cognitive difference rather than as a cognitive deficit. This framing has enabled us to examine the ways in which standard tools (e.g., symbolic notation) were not 
always fully accessible to Dylan. Unlike a deficit approach, which would simply determine that Dylan solved problems more slowly than her peers, our analysis revealed that the compensatory strategies she implemented to gain access often required more time and effort. This framing not only provides unique insights into dyscalculia but also suggests an alternative approach for instruction. The "problems" Dylan encountered were in the accessibility of standard mathematical tools. This suggests that rather than attempting to change or fix something about the student-the focus of most current intervention approaches (e.g., [21]) — we need to consider how to address students' issues of access. This may be accomplished through the development and use of alternative tools (e.g., providing students with graph paper and allowing them to use colored pens), or by helping the student develop compensatory strategies. This shift from deficit to difference is not mere semantics but fundamentally changes the perceived origin of the disability. This reframing is not only important for researchers, but for teachers and parents. Teachers who see student difficulties as resulting from an internal characteristic of the student (i.e., deficits) are less likely to see instruction as a productive approach to help the student learn $[22,23]$. By identifying the inaccessibility of standard tools, it empowers educators to consider how to address these access issues and places the onus for addressing them on instruction. This paper has established the benefits of understanding dyscalculia in terms of difference because it highlights both issues of access in the material tools, suggests that designing more accessible tools may provide greater access, and highlights how individuals can compensate to gain access to otherwise inaccessible content.

\subsection{Countering the Myth: Students with Dyscalculia Cannot Learn Higher Level Mathematics}

Although there is a pervasive belief that students with dyscalculia cannot be successful in mathematics, Dylan clearly counters this myth. She was able to complete her statistics degree at UC Berkeley and go on to work as a data analyst. Dylan's success was largely due to her determination and "brute force" refusing to give up. She encountered both a college system that did not provide sufficient accommodations as well as policies and procedures which marginalized her participation in mathematics. She was forced to develop and continuously refine systems on her own to enable her to complete upper division mathematics classes. She had to pay for tutors and take classes multiple times in order to pass them. Clearly the onus should not be on the student like it was in Dylan's case. In order to sufficiently support students, it is important to understand the issues of access that students will experience across mathematics topics and begin to design alternative tools to help students compensate.

\subsection{Countering the Myth: Students Must Master the "Basics" to Succeed}

Because mathematics is often seen as a hierarchical topic domain, it may feel sensible that students need to first have a foundation in the basics before progressing on to higher level mathematics. Dylan's experience helps challenge this widely-held belief and demonstrates how it may be exclusionary to require particular kinds of competency before enabling a student to explore more complex concepts. Dylan had difficulty comparing unit fractions, but was able to understand and manipulate complicated rational expressions modeling statistical phenomenon. Dylan still struggled to retrieve basic number combinations while she was taking linear algebra, but she was able to make sense of complex mathematics concepts and complete a major in statistics. This suggests that there may be some students who never master the "basics," and that these students should not be excluded from participation in higher level mathematics. This raises further questions around the use of remedial mathematics courses in college, which not only limit students' access to college level mathematics, but are identified as the primary barrier for students in completing their degrees [24].

\subsection{Countering the Myth: Speed and Efficiency Are Important}

Research on dyscalculia that quantifies student performance based on speed and accuracy or classifies some approaches as "immature" because they are less efficient (e.g., [25]) has contributed 
to this problematic myth. Dylan's use of her compensatory strategies often resulted in her taking more time and often required more steps. Dylan was told by multiple TAs that she needed to shorten her solutions. However, these compensatory strategies were precisely what enabled her to access the mathematics. Speed and efficiency were not essential components of Dylan's success. This suggests that instruction that prioritizes speed and efficiency in mathematics can have detrimental results for students and may marginalize students' participation in higher level mathematics. Dylan's case suggests that if we want mathematics to be accessible for all, we should encourage multiple solution paths, even those that do not adhere to the mathematic aesthetic of economy of notation.

\subsection{Removing Structural Barriers}

Dylan encountered numerous structural and systemic barriers. In this section, we identify the barriers that Dylan described and recommend approaches to remove these barriers. In doing so, we raise questions about mathematics disciplinary norms which may unintentionally perpetuate these systemic barriers.

Dylan described time as being the biggest issue for her in succeeding and completing her statistics major. She was allowed the standard accommodation of time-and-a-half on exams, but this was often woefully insufficient for her to implement the compensatory strategies she needed to enable her to access the mathematics. Dylan called this time constraint "artificial" and notes that in her career as a data analyst she was never under this kind of intense time pressure. This raises the question: why do mathematics tests have a time limit? Is it because the mathematics community endorses the myth that mathematics is about speed and efficiency? Dylan would have been much more successful if she had been able to take untimed assessments. Weeder classes and timed assessments limit participation in higher level mathematics and in turn other STEM fields. Disproportionate representation may be largely due to these kinds of policies and practices which privilege a certain kind of student and a certain way of doing mathematics. We should begin to hold math departments accountable for the disproportionate representation of students who survive their "weeder" classes and require justification for constraints placed on students in terms of time. We argue that structural components of "weeder" mathematics classes and timed tests should be rethought if we hope to address the racial, gender, and disability disparities within the STEM fields.

Another continual source of frustration for Dylan was that she was unable to get sufficient accommodations or financial support for tutoring. Her primary "accommodation" was that she was allowed to waive the university mathematics requirement-an exclusionary policy and practice. She bore the financial responsibility for paying to retake courses and for support from tutors. The tutors that she paid were not skilled in providing the kinds of support she needed. She asked tutors to translate symbols into words and help her understand the applicability of concepts that she was learning. These mathematics graduate students were unable to do so. This calls us to consider how we define mathematics proficiency. Clearly, these tutors were deemed skilled in mathematics given their status as mathematics graduate students at a prestigious university, and yet they could not unpack the meaning behind the symbols they so effortlessly manipulated. How might we want all professors and TAs to be able to translate symbols into words and contextualize abstract mathematics concepts in meaningful real world applications? In raising this question, we reframe Dylan's need for symbol translation as a desirable goal that should be considered part of standard mathematical proficiency.

To address the systematic marginalization of individuals with disabilities, colleges should evaluate their disability accommodation practices to determine if they are exclusionary, as with the ones Dylan encountered. True accommodations for Dylan would have been (a) untimed assessments; (b) financial support for tutors who were qualified to provide support; and (c) materials which provided a translation of notation into words and concrete examples of the concepts she was learning. As colleges revise accommodation policies, it is essential to involve individuals with disabilities in the process of assessing current practices and determining what policies and practices remain oppressive and exclusionary. 


\section{Conclusions}

Dylan's experience as a statistician with dyscalculia provides evidence countering many common myths about mathematics and ability. She provides a clear example of how students with dyscalculia can be successful in upper division mathematics and have a career in the field. Her experiences highlight both how she encountered issues of access with standard mathematical forms and also how she was able to develop a complex repository of strategies to compensate. In completing her degree, Dylan was not disabled by how her brain processed number differently, but by the systemic policies and procedures which marginalized her participation in mathematics. In order to fully counter entrenched myths about ability and mathematics we believe it is necessary to dismantle these oppressive policies and procedures which artificially constrain who has access to mathematics.

Author Contributions: Katherine Lewis and Dylan Lynn participated in all stages of this research project, including, design, data collection, and analysis. Katherine Lewis wrote the initial draft of the paper with Dylan Lynn providing substantial feedback and recommendations.

Acknowledgments: A grant from the University of Washington covered the cost of publishing in open access.

Conflicts of Interest: The authors declare no conflict of interest. The founding sponsors had no role in the design of the study; in the collection, analyses, or interpretation of data; in the writing of the manuscript, and in the decision to publish the results.

\section{References}

1. Lewis, K.E.; Lynn, D.M. An insider's view of a mathematics learning disability: Compensating to gain access to fractions. Investig. Math. Learn. 2018, in press. [CrossRef]

2. Lewis, K.E.; Lynn, D.M. Access through compensation: Emancipatory view of a mathematics learning disability. Cognit. Instruct.. in press.

3. Shalev, R.S. Prevalence of developmental dyscalculia. In Why is Math So Hard for Some Children? The Nature and Origins of Mathematical Learning Difficulties and Disabilities; Berch, D.B., Mazzocco, M.M.M., Eds.; Paul, H. Brookes: Baltimore, MD, USA, 2007; pp. 49-60.

4. Devine, A.; Hill, F.; Carey, E.; Szúcs, D. Cognitive and emotional math problems largely dissociate: Prevalence of developmental dyscalculia and mathematics anxiety. J. Educ. Psychol. 2018, 110, 431-444. [CrossRef]

5. Butterworth, B. Foundational numerical capacities and the origins of dyscalculia. Trends Cogn. Sci. 2010, 14, 534-541. [CrossRef] [PubMed]

6. Desoete, A.; Ceulemans, A.; De Weerdt, F.; Pieters, S. Can we predict mathematical learning disabilities from symbolic and non-symbolic comparison tasks in kindergarten? Findings from a longitudinal study. Br. J. Educ. Psychol. 2012, 82, 64-81. [CrossRef] [PubMed]

7. Butterworth, B.; Varma, S.; Laurillard, D. Dyscalculia: From brain to education. Science 2011, 332, 1049-1053. [CrossRef] [PubMed]

8. Mazzocco, M.M.M.; Devlin, K.T.; McKenney, S.J. Is it a fact? Timed arithmetic performance of children with mathematical learning disabilities (MLD) varies as a function of how MLD is defined. Dev. Neuropsychol. 2008, 33, 318-344. [CrossRef] [PubMed]

9. Mazzocco, M.M.M.; Myers, G.F.; Lewis, K.E.; Hanich, L.B.; Murphy, M.M. Limited knowledge of fraction representations differentiates middle school students with mathematics learning disability (dyscalculia) versus low mathematics achievement. J. Exp. Child Psychol. 2013, 115, 371-387. [CrossRef] [PubMed]

10. Murphy, M.M.; Mazzocco, M.M.M.; Hanich, L.B.; Early, M.C. Cognitive characteristics of children with mathematics learning disability (MLD) vary as a function of the cutoff criterion used to define MLD. J. Learn. Disabil. 2007, 40, 458-478. [CrossRef] [PubMed]

11. Geary, D.C. Mathematical disabilities: Reflections on cognitive, neuropsychological, and genetic components. Learn. Individ. Differ. 2010, 20, 130-133. [CrossRef] [PubMed]

12. Geary, D.C.; Hoard, M.K.; Bailey, D.H. Fact Retrieval Deficits in Low Achieving Children and Children with Mathematical Learning Disability. J. Learn. Disabil. 2012, 45, 291-307. [CrossRef] [PubMed]

13. Lewis, K.E.; Fisher, M.B. Taking stock of 40 years of research on mathematical learning disability: Methodological issues and future directions. J. Res. Math. Educ. 2016, 47, 338-371. [CrossRef] 
14. Swanson, H.L. Cognitive Aspects of Math Disabilities. In Why is Math So Hard for Some Children? The Nature and Origins of Mathematical Learning Difficulties and Disabilities; Berch, D.B., Mazzocco, M.M.M., Eds.; Paul H Brookes Publishing: Baltimore, MD, USA, 2007; pp. 133-146. ISBN 978-1-55766-864-6.

15. Oliver, M. Changing the social relations of research production? Disabil. Handicap Soc. 1992, 7, $101-114$. [CrossRef]

16. Vygotsky, L.S. Introduction: Fundamentals problems of defectology. In The Collected Works of L. S. Vygotsky, Volume 2: The Fundamentals of Defectology; Rieber, R.W., Carton, A.S., Eds.; Plenum Press: London, NY, USA, 1929; ISBN 0-306-42442-8.

17. Thaler, L.; Arnott, S.R.; Goodale, M.A. Neural correlates of natural human echolocation in early and late blind echolocation experts. PLoS ONE 2011, 6, 1-16. [CrossRef] [PubMed]

18. Mercer, G. From critique to practice: Emancipatory disability research. In Implementing the Social Model of Disability: Theory and Research; Barnes, C., Mercer, G., Eds.; The Disability Press: Leeds, UK, 2004; pp. 118-137.

19. Barnes, C. "Emancipatory disability research": Project or process? J. Res. Spec. Educ. Needs 2002, 2, 1-8. [CrossRef]

20. Stone, E.; Priestley, M. Parasites, pawns and partners: Disability research and the role of non-disabled researchers. Br. J. Sociol. 1996, 47, 699-716. [CrossRef] [PubMed]

21. Moser Opitz, E.; Freesemann, O.; Prediger, S.; Grob, U.; Matull, I.; Hußmann, S. Remediation for students with mathematics difficulties: An intervention study in middle schools. J. Learn. Disabil. 2017, 50, 724-736. [CrossRef] [PubMed]

22. Jackson, K.; Gibbons, L.; Sharpe, C.J. Teachers' views of students' mathematical capabilities: Challenges and possibilities for ambitious reform. Teach. Coll. Rec. 2017, 119, 1-43.

23. Wilhelm, A.G.; Munter, C.; Jackson, K. Examining relations between teachers' explanations of sources of students' difficulty in mathematics and students' opportunities to learn. Elem. Sch. J. 2017, 117, 345-370. [CrossRef]

24. Silva, E.; White, T. Pathways to Improvement: Using Psychological Strategies to Help College Students Master Developmental Math; Carnegie Foundation: Stanford, CA, USA, 2013.

25. Geary, D.C.; Bow-Thomas, C.C.; Yao, Y. Counting knowledge and skill in cognitive addition: A comparison of normal and mathematically disabled children. J. Exp. Child Psychol. 1992, 54, 372-391. [CrossRef] 